\title{
Serious Games for Nutritional Education: Online Survey on Preferences, Motives, and Behaviors Among Young Adults at University
}

Sophie Laura Holzmann ${ }^{1}$, MSc; Hanna Schäfer ${ }^{2}$, MSc; David Alexander Plecher ${ }^{3}$, MSc; Lynne Stecher ${ }^{1}, \mathrm{PhD}$; Gudrun Johanna Klinker ${ }^{3}$, PhD; Georg Groh ${ }^{2}$, PhD; Hans Hauner ${ }^{1}, \mathrm{MD}$; Christina Holzapfel ${ }^{1}, \mathrm{PhD}$

\footnotetext{
${ }^{1}$ Institute for Nutritional Medicine, Else Kröner-Fresenius-Center for Nutritional Medicine, School of Medicine, Technical University of Munich, Munich, Germany

${ }^{2}$ Research Group Social Computing, Department of Informatics, Technical University of Munich, Garching, Germany

${ }^{3}$ Chair for Computer Aided Medical Procedures \& Augmented Reality, Department of Informatics, Technical University of Munich, Garching, Germany
}

\section{Corresponding Author:}

Christina Holzapfel, PhD

Institute for Nutritional Medicine, Else Kröner-Fresenius-Center for Nutritional Medicine

School of Medicine

Technical University of Munich

Georg-Brauchle-Ring 62

Munich,

Germany

Phone: 498928924923

Fax: 498928924922

Email: christina.holzapfel@tum.de

\section{Abstract}

Background: Data on nutritional information and digital gameplay are limited among young adults in Germany.

Objective: This survey aimed to gather data on nutritional information sources and digital games for nutritional education (preferences, motives, and behaviors) among young adults at both Munich universities in Germany.

Methods: An online survey was developed by an multidisciplinary research group using EvaSys, an in-house survey software. The questionnaire (47 items) covered questions about baseline characteristics (eg, housing situation and weight), nutrition (eg, nutritional information sources), and digital (nutritional) gameplay (eg, preferences, motives, and behaviors). A feedback field was also provided. This publication is based on a selection of 20 questions ( 7 baseline characteristics, 2 nutrition, 11 gameplay). Young adults, primarily Munich university students aged from 18 to 24 years, were invited to participate by digital and nondigital communication channels between 2016 and 2017. Statistical analyses were performed using Excel 2013 (Microsoft Corp) and R version 3.1.3 (R Foundation for Statistical Computing).

Results: In total, 468 young adults (342/468, 73.1\% women; 379/468, 81.0\% university students) participated. Most of the participants $(269 / 468,57.5 \%)$ were aged 18 to 24 years with a BMI in the normal weight range $(346 / 447,77.4 \%)$. Mean body weight was 65.5 [SD 14.0] kg. Most participants reported getting nutritional information from the internet $(372 / 467,79.7 \%)$ and printed media $(298 / 467,63.8 \%)$, less than $1.0 \%$ (2/467, 0.4\%) named digital games. Apps (100/461, 21.7\%) and university/workplace $(146 / 461,31.7 \%)$ were the most desired sources for additional information about nutrition, while $10.0 \%$ $(46 / 461,10.0 \%)$ of participants stated wanting digital games. Almost two-thirds $(293 / 468,62.6 \%)$ of participants played digital games, while one-fifth $(97 / 456,21.3 \%)$ played digital games daily using smartphones or tablets. Finally, most respondents $(343 / 468,73.3 \%)$, mainly women, expressed interest in obtaining nutritional information during digital gameplay. However, significant gender differences were shown for nutritional acquisition behaviors and digital gameplay preferences, motives, and behaviors.

Conclusions: Our survey population reported playing digital games (especially men) and wanting nutritional information during digital gameplay (especially women). Furthermore, university or workplace are named as preferred settings for nutritional information. Therefore, a digital game app might have the potential to be a tool for nutritional education among young adults within the university or workplace environment. 
(JMIR Serious Games 2020;8(2):e16216) doi: 10.2196/16216

\section{KEYWORDS}

nutrition; information sources; serious games; digital gameplay; preferences; motives; behavior; university students; survey

\section{Introduction}

\section{Background}

The prevalence of overweight and obesity reached global pandemic and represents a major public health concern [1]. In Germany, $7.2 \%$ of young adults (aged 18 to 24 years) are affected by obesity [2]. Moreover, it is reported that young adults of Western nations are more vulnerable to weight gain than any other age group [3]. Obesogenic environments with increases in energy-dense foods and sedentary behaviors are the main causes for the development of overweight and obesity $[1,3]$. According to the German National Consumption Study II, adolescents (aged 15 to 18 years) and young adults (aged 19 to 24 years) show the highest daily intake of free sugar [4]. This also applies at the global level and for other nutrients or food groups (eg, low intake of fruits and vegetables) [3,5-7].

To address overweight and obesity among young adults, nutritional education programs can be used within different settings (eg, workplace, home, community, health care, and educational facilities) at both the individual and population level $[1,8,9]$. These programs are applied to change knowledge, attitudes, and beliefs about healthy dietary behaviors and also affect the dietary behaviors themselves [10-12]. For instance, serious games present a novel digital approach to nutritional education by conveying nutritional information in an entertaining format $[13,14]$. In recent years, the market for games and number of gaming individuals has increased. In 2017, 34.1 million people in Germany played computer and video games [15]. The literature indicates that serious gameplay might be an appealing and effective tool for nutritional education and dietary behavior change $[14,16]$. A few studies investigated the effects of serious games on nutritional education among (young) adults [12]. According to a narrative review, nutritional knowledge can be increased in young adults (aged 18 to 35 years) through game-based nutritional interventions [12]. A randomized controlled study among 40 persons (80\% women; mean age 20 years) showed that playing a role-play computer game for 3 weeks improved knowledge about nutrition and weight management for the short term [17]. According to a 3 -month study among 47 women with an average age of 30 years, playing a serious computer game resulted in significant improvements of body mass index and nutritional knowledge from baseline to the end of the study [18].

\section{Aim}

The aim of this online survey was to collect data on young adults' nutritional information sources and preferences, motives, and behaviors regarding a digital game for nutritional education purposes.

\section{Methods}

\section{Recruitment}

The Ethical Committee of the School of Medicine at the Technical University of Munich approved this open online survey (ethical vote: 164/16S), which was performed from December 2016 to July 2017 in Munich, the third largest city in Germany, with approximately 1.5 million inhabitants. The survey invitation included a password and link guiding participants to the online survey. The recruitment of young adults was conducted mainly through digital communication channels (eg, newsletters, social media, and email) at both Munich universities (Technical University of Munich and Ludwig-Maximilians University) and primarily included students, graduates, and employees. Furthermore, recruitment was extended by social media (eg, Facebook), printed flyers (eg, at canteens), and other student-affiliated distribution channels (eg, Technical University of Munich General Student Committee).

Since the exact number of invitations is unknown, it was not possible to calculate a response rate. The following inclusion criteria were applied: understanding of the German language, willingness to participate, and internet access. All participants gave informed consent to participate.

The first page of the survey provided information about the research team, aim of the survey, target group (young adults aged from 18 to 24 years), and instruction (eg, completion time of 5 to 10 minutes). Finally, information about data privacy and protection (eg, voluntary participation confidential, no personal data) was provided. Participants had to confirm the data privacy statement before starting the survey. Each question had to be answered to continue. No incentives were offered to the participants.

\section{Questionnaire: Development and Design}

The 47-item questionnaire was developed by an multidisciplinary team of nutritionists, economists, sociologists, and computer scientists using EvaSys V7.0 (2101) survey software. Questions (closed, semi-open, open; single or multiple choice) referred to nutrition (16 questions), digital games (22 questions), personal characteristics (8 questions), and feedback (1 field). Wherever possible, a "don't know," "no answer applies," or "other" option was provided. This questionnaire represents a revised version of a questionnaire developed by the same multidisciplinary research team and previously used in a survey among children and adolescents [19]. Age-specific modifications were made to ensure age adequacy. Similar to our previous survey [19], this work is based on a selection of 20 (7 baseline characteristics, 2 nutrition, 11 gameplay) of the 47 questions. Questions not presented were mainly focused on technical issues for design and development of a game. 


\section{Statistical Analyses}

Only completed questionnaires were analyzed. Integrity and plausibility checks were performed. Questionnaires with missing answers for 8 or more questions or invalid answers were excluded. Descriptive data analyses (frequencies, percentages, standard deviations, and means) were performed using Excel 2013 (Microsoft Corp). Gender differences in responses were assessed using Pearson chi-square tests for categorical variables. These analyses were performed using $\mathrm{R}$ version 3.1.3 ( $\mathrm{R}$ Foundation for Statistical Computing). $P$ values of $<.05$ were considered statistically significant. The analyses are based on 20 out of 47 questions.

\section{Results}

\section{Participant Characteristics}

Table 1 presents the sociodemographic and anthropometric characteristics of the participants. In total, 468 young adults (342/468, 73.1\% women), primarily university students (379/468, 81.0\%), participated. Nonstudent participants were mainly those previously affiliated with a university (eg, graduates) or academic staff (eg, research assistants). Most participants were aged between 18 and 24 years (269/468, $57.5 \%$ ). Body weight ranged from $35.9 \mathrm{~kg}$ to $190.0 \mathrm{~kg}$ (mean 65.5 [SD 14.0] kg) and height varied between $1.50 \mathrm{~m}$ and 2.02 $\mathrm{m}$ (mean 1.68 [SD 0.09] $\mathrm{m}$ ). According to the body mass index (mean 22.3 [SD 3.6] kg/m²), participants were mostly normal weight $(346 / 447,77.4 \%)$. Most participants either lived with their family $(193 / 468,41.2 \%)$ or in a flat/house share $(166 / 468$, $35.5 \%$ ).

Table 1. Characteristics of survey participants.

\begin{tabular}{|c|c|}
\hline Characteristics & Value, $\mathrm{n}(\%)$ \\
\hline \multicolumn{2}{|l|}{ Sociodemography $(n=468)$} \\
\hline \multicolumn{2}{|l|}{ Age in years } \\
\hline $18-19$ & $24(5.1)$ \\
\hline $20-21$ & $84(18.0)$ \\
\hline $22-24$ & $161(34.4)$ \\
\hline$>24$ & $199(42.5)$ \\
\hline \multicolumn{2}{|l|}{ Sex } \\
\hline Female & $342(73.1)$ \\
\hline Male & $126(26.9)$ \\
\hline \multicolumn{2}{|l|}{ Home environment } \\
\hline Family & $193(41.2)$ \\
\hline Flat/house share & $166(35.5)$ \\
\hline Alone & $95(20.3)$ \\
\hline Other & $14(3.0)$ \\
\hline \multicolumn{2}{|l|}{ Anthropometry $(n=447)$} \\
\hline \multicolumn{2}{|l|}{ Body mass index } \\
\hline Underweight $\left(<18.5 \mathrm{~kg} / \mathrm{m}^{2}\right)$ & $34(7.6)$ \\
\hline Normal weight $\left(18.5-24.9 \mathrm{~kg} / \mathrm{m}^{2}\right)$ & $346(77.4)$ \\
\hline Overweight $\left(25.0-29.9 \mathrm{~kg} / \mathrm{m}^{2}\right)$ & $54(12.1)$ \\
\hline Obesity ( $\geq 30.0 \mathrm{~kg} / \mathrm{m}^{2}$ ) & $13(2.9)$ \\
\hline
\end{tabular}

\section{Sources of Nutritional Information}

Table 2 shows digital and nondigital sources of nutritional information that participants currently use or desire to additionally use. Most participants $(372 / 467,79.7 \%)$ responded that they use the internet for obtaining digital nutritional information (nonsignificant gender differences) with one-third $(160 / 467,34.4 \%)$ reported using social networks (significantly more women than men; $P=.001$ ).
Regarding nondigital sources, the majority (298/467, 63.8\%) of respondents stated that they were informed about nutrition via books and newspapers (significantly more women than men; $P<.001)$. The second most currently used nondigital information sources were partner and family $(218 / 467,46.7 \%)$ and friends (201/467, 43.0\%; nonsignificant gender differences for both items), followed by university and workplace (164/467, 35.1\%; significantly more women than men; $P=.001)$. 
More than a fifth $(100 / 461,21.7 \%)$ of participants would like to receive additional digital nutritional information via apps (nonsignificant gender differences). Television (67/461, 14.5\%), internet $(65 / 461,14.1 \%)$, and social networks $(71 / 461,15.4 \%)$ were each requested as nutritional information sources by almost $15 \%$ of participants. Significant gender differences occurred for social networks only (significantly more women than men; $P=.04)$. The main desired nondigital source for additional information about nutrition was university and workplace
$(146 / 461,31.7 \%)$ followed by books and newspapers (52/461, $11.3 \%)$. No statistically significant differences were found between women and men.

Specifically regarding digital games, only two participants $(2 / 467,0.4 \%)$ responded that they are currently using digital games for nutritional information (nonsignificant gender differences), but $10.0 \%$ (46/461) would like to use digital games as an additional nutritional information source (significantly more women than men; $P=.003)$.

Table 2. Digital and nondigital sources of nutritional information (multiple responses allowed).

\begin{tabular}{|c|c|c|c|c|}
\hline Source and characteristic & All, n (\%) & Female, n (\%) & Male, n (\%) & $P$ value \\
\hline \multicolumn{5}{|l|}{ Currently used $^{a}(n=467)$} \\
\hline \multicolumn{5}{|l|}{ Digital } \\
\hline Television & $98(21.0)$ & $73(21.3)$ & $25(20.0)$ & .75 \\
\hline Internet & $372(79.7)$ & $271(79.2)$ & $101(80.8)$ & .71 \\
\hline Social networks & $160(34.4)$ & $132(38.6)$ & $28(22.4)$ & .001 \\
\hline Apps & $66(14.1)$ & $61(17.8)$ & $5(4.0)$ & $<.001$ \\
\hline Digital games & $2(0.4)$ & $2(0.6)$ & $0(0)$ & .39 \\
\hline \multicolumn{5}{|l|}{ Nondigital } \\
\hline University and workplace & $164(35.1)$ & $135(39.5)$ & $29(23.2)$ & .001 \\
\hline Partner and family & $218(46.7)$ & $153(44.7)$ & $65(52.0)$ & .16 \\
\hline Friends & $201(43.0)$ & $153(44.7)$ & $48(38.4)$ & .22 \\
\hline Books and newspapers & $298(63.8)$ & $237(69.3)$ & $61(48.8)$ & $<.001$ \\
\hline \multicolumn{5}{|l|}{ Other } \\
\hline Unknown & $109(23.3)$ & $81(23.7)$ & $28(22.4)$ & .77 \\
\hline No answer applies & $7(1.5)$ & $3(0.9)$ & $4(3.2)$ & .07 \\
\hline \multicolumn{5}{|l|}{ Additionally desired $^{b}(n=461)$} \\
\hline \multicolumn{5}{|l|}{ Digital } \\
\hline Television & $67(14.5)$ & $54(16.1)$ & $13(10.4)$ & .13 \\
\hline Internet & $65(14.1)$ & $44(13.1)$ & $21(16.8)$ & .31 \\
\hline Social networks & $71(15.4)$ & $59(17.6)$ & $12(9.6)$ & .04 \\
\hline Apps & $100(21.7)$ & $78(23.2)$ & $22(17.6)$ & .19 \\
\hline Digital games & $46(10.0)$ & $42(12.5)$ & $4(3.2)$ & .003 \\
\hline \multicolumn{5}{|l|}{ Nondigital } \\
\hline University and workplace & $146(31.7)$ & $108(32.1)$ & $38(30.4)$ & .72 \\
\hline Partner and family & $30(6.5)$ & $24(7.1)$ & $6(4.8)$ & .37 \\
\hline Friends & $29(6.3)$ & $23(6.8)$ & $6(4.8)$ & .42 \\
\hline Books and newspapers & $52(11.3)$ & $42(12.5)$ & $10(8.0)$ & .18 \\
\hline \multicolumn{5}{|l|}{ Other } \\
\hline Unknown & $40(8.7)$ & $35(10.4)$ & $5(4.0)$ & .03 \\
\hline No answer applies & $173(37.5)$ & $111(33.0)$ & $62(49.6)$ & .001 \\
\hline
\end{tabular}

${ }^{\mathrm{a}}$ How are you currently informed about nutrition?

${ }^{b}$ How would you like to be additionally informed about nutrition? 
Digital Gameplay: Preferences, Motives, and Behaviors

Table 3 shows that more than one-half of the participants (293/468, 62.6\%) reported playing digital games. Men were significantly more likely to play digital games (100/126, 79.4\%) compared with women $(193 / 342,56.4 \% ; P<.001)$. The most frequent answer regarding the preferred team composition within a digital game was friends $(274 / 464,59.1 \%)$. A similar proportion of participants responded with partner and family $(193 / 464,41.6 \%)$ and individuals with the same eating behavior $(188 / 464,40.5 \%)$. There were no statistically significant differences between women and men.

The questionnaire also asked for the most preferred game character in digital games. Nearly half of participants $(226 / 468$, $48.3 \%)$ preferred a human being while almost a fifth $(89 / 468$, $19.0 \%$ ) preferred a fantasy character (nonsignificant gender differences), followed by a cute animal (51/468, 10.9\%), which was significantly more desired by women than by men $(P=.01)$.

In addition to these preferences, Table 3 presents the frequency of digital gameplay by device. The most frequent answer of participants who reported playing digital games on smartphones or tablets was daily $(97 / 456,21.3 \%)$, followed by weekly $(66 / 456,14.5 \%)$ and monthly $(65 / 456,14.3 \%)$, with no statistically significant differences between women and men. Half of the participants $(222 / 453,49.0 \%)$, who use digital games, reported short gameplay ( $\leq 30$ minutes).

One-fifth $(99 / 463,21.4 \%)$ of participants reported that they play digital games for more than 60 minutes continuously on
PCs or consoles, and one-eighth $(57 / 463,12.3 \%)$ reported doing so for exactly 60 minutes (significantly more men than women: $P<.001$ vs $P=.003)$.

More than $40 \%$ of the participants reported mainly playing digital games if they felt like gaming (199/442, 45.0\%; significantly more men than women; $P<.001)$ or were bored (190/442, 43.0\%; nonsignificant gender differences; $P=.13)$. In total, $10.4 \%(46 / 442)$ of participants reported playing digital games when they are happy (significantly more men than women; $P<.001)$. Moreover, one-third of participants (153/442, $34.6 \%)$ reported playing digital games often alone at home (significantly more men than women; $P=.003$ ), and one-fifth $(101 / 442,22.9 \%)$ stated that they played digital games mainly on the go (significantly more women than men; $P=.03$ ). Significantly more men than women reported playing digital games with friends $(P<.001)$.

Participants were asked whether they would like to receive nutritional information by playing digital games. Nearly two-thirds (293/468, 62.6\%) of participants expressed an interest in receiving nutritional information during gameplay, with women reporting this significantly more often than men $(P<.001)$. Moreover, almost three-quarters indicated they preferred being educated via answering quiz questions (323/463, $69.8 \%)$ or completing tasks $(333 / 463,71.9 \%)$ during digital gameplay, with significantly more women than men reporting both of these (quiz $P<.001$ vs task $P=.001$ ). In contrast, significantly more men than women stated that they don't want to learn anything during digital gameplay $(P<.001)$. 
Table 3. Digital gameplay: preferences, motives, and behaviors.

\begin{tabular}{|c|c|c|c|c|}
\hline Digital gameplay and characteristics & All, n (\%) & Female, n (\%) & Male, $\mathrm{n}(\%)$ & $P$ value \\
\hline \multicolumn{5}{|l|}{ Preferences } \\
\hline \multicolumn{5}{|l|}{ Team composition $^{\mathrm{a}, \mathrm{b}}(\mathrm{n}=464)$} \\
\hline Partner and family & $193(41.6)$ & $144(42.5)$ & $49(39.2)$ & .53 \\
\hline Friends & $274(59.1)$ & $199(58.7)$ & $75(60.0)$ & .80 \\
\hline Same hobbies & $132(28.4)$ & $97(28.6)$ & $35(28.0)$ & .90 \\
\hline Same eating behavior & $188(40.5)$ & $144(42.5)$ & $44(35.2)$ & .16 \\
\hline No similarities & $109(23.5)$ & $79(23.3)$ & $30(24.0)$ & .88 \\
\hline Other & $26(5.6)$ & $20(5.9)$ & $6(4.8)$ & .65 \\
\hline No team & $37(8.0)$ & $25(7.4)$ & $12(9.6)$ & .43 \\
\hline \multicolumn{5}{|l|}{ Teammates $^{c, d}(n=445)$} \\
\hline$\leq 5$ & $116(26.1)$ & $67(20.7)$ & $49(40.2)$ & $<.001$ \\
\hline $6-10$ & $11(2.5)$ & $5(1.5)$ & $6(4.9)$ & .04 \\
\hline$>10$ & $8(1.8)$ & $3(0.9)$ & $5(4.1)$ & .03 \\
\hline Alone & $130(29.2)$ & $98(30.3)$ & $32(26.2)$ & .40 \\
\hline I do not play & $152(34.2)$ & $129(39.9)$ & $23(18.9)$ & $<.001$ \\
\hline I do not know & $28(6.3)$ & $21(6.5)$ & $7(5.7)$ & .77 \\
\hline \multicolumn{5}{|l|}{ Game character $^{\mathrm{c}, \mathrm{e}}(\mathrm{n}=\mathbf{4 6 8})$} \\
\hline Cute animal & $51(10.9)$ & $45(13.2)$ & $6(4.8)$ & .01 \\
\hline Impressive animal & $23(4.9)$ & $16(4.7)$ & $7(5.6)$ & .70 \\
\hline Fantasy animal & $20(4.3)$ & $15(4.4)$ & $5(4.0)$ & .84 \\
\hline Fantasy character & $89(19.0)$ & $62(18.1)$ & $27(21.4)$ & .42 \\
\hline Human being & $226(48.3)$ & $163(47.7)$ & $63(50.0)$ & .65 \\
\hline Other & $26(5.6)$ & $18(5.3)$ & $8(6.3)$ & .65 \\
\hline No answer applies & $33(7.1)$ & $23(6.7)$ & $10(7.9)$ & .65 \\
\hline \multicolumn{5}{|l|}{ Motives $^{\mathrm{a}, \mathrm{f}}(\mathrm{n}=\mathbf{4 4 2})$} \\
\hline \multicolumn{5}{|l|}{ Emotion } \\
\hline Pleasure & $199(45.0)$ & $123(38.3)$ & $76(62.8)$ & $<.001$ \\
\hline Happiness & $46(10.4)$ & $20(6.2)$ & $26(21.5)$ & $<.001$ \\
\hline Sadness & $20(4.5)$ & $13(4.0)$ & $7(5.8)$ & .43 \\
\hline Boredom & $190(43.0)$ & $131(40.8)$ & $59(48.8)$ & .13 \\
\hline \multicolumn{5}{|l|}{ Setting } \\
\hline Friends & $36(8.1)$ & $16(5.0)$ & $20(16.5)$ & $<.001$ \\
\hline On the go & $101(22.9)$ & $82(25.5)$ & $19(15.7)$ & .03 \\
\hline University and workplace & $44(10.0)$ & $32(10.0)$ & $12(9.9)$ & .99 \\
\hline Alone at home & $153(34.6)$ & $98(30.5)$ & $55(45.5)$ & .003 \\
\hline Other situations & $27(6.1)$ & $18(5.6)$ & $9(7.4)$ & .47 \\
\hline \multicolumn{5}{|l|}{ Other } \\
\hline I do not play & $154(34.8)$ & $131(40.8)$ & $23(19.0)$ & $<.001$ \\
\hline I do not know & $0(0)$ & $0(0)$ & $0(0)$ & - \\
\hline \multicolumn{5}{|l|}{ Behaviors } \\
\hline Digital gameplay ${ }^{c, g}(n=468)$ & & & & \\
\hline
\end{tabular}




\begin{tabular}{|c|c|c|c|}
\hline Digital gameplay and characteristics & All, n (\%) & Female, n $(\%)$ & Male, n (\%) \\
\hline Yes & $293(62.6)$ & $193(56.4)$ & $100(79.4)$ \\
\hline No & $175(37.4)$ & $149(43.6)$ & $26(20.6)$ \\
\hline \multicolumn{4}{|c|}{ Duration of digital gameplay (smartphone/tablet) ${ }^{\mathrm{c}, \mathrm{h}}(\mathrm{n}=\mathbf{4 5 3})$} \\
\hline$\leq 30$ minutes & $222(49.0)$ & $160(48.6)$ & $62(50.0)$ \\
\hline 60 minutes & $5(1.1)$ & $5(1.5)$ & $0(0.0)$ \\
\hline$>60$ minutes & $4(0.9)$ & $2(0.6)$ & $2(1.6)$ \\
\hline I do not play & $212(46.8)$ & $155(47.1)$ & $57(46.0)$ \\
\hline I do not know & $10(2.2)$ & $7(2.1)$ & $3(2.4)$ \\
\hline
\end{tabular}

Duration of digital gameplay $(\mathrm{PC} / \text { console })^{\mathrm{c}, \mathrm{i}}(\mathrm{n}=\mathbf{4 6 3})$

$\leq 30$ minutes
60 minutes
$>60$ minutes
I do not play
I do not know

$50(10.8)$
$57(12.3)$
$99(21.4)$
$248(53.6)$
$9(1.9)$

$\begin{array}{lll}36(10.7) & 14(11.1) & .90 \\ 32(9.5) & 25(19.8) & .003 \\ 45(13.4) & 54(42.9) & <.001 \\ 218(64.7) & 30(23.8) & <.001 \\ 6(1.8) & 3(2.4) & .68\end{array}$

Frequency of digital gameplay (smartphone/tablet) ${ }^{\mathrm{c}, \mathrm{j}}(\mathrm{n}=\mathbf{4 5 6})$

$$
\begin{aligned}
& \text { Daily } \\
& \text { Weekly } \\
& \text { Monthly } \\
& \text { I do not play } \\
& \text { I do not know }
\end{aligned}
$$

97 (21.3)

66 (14.5)

65 (14.3)

$220(48.2)$

$8(1.8)$

Frequency of digital gameplay $(\mathrm{PC} / \text { console })^{\mathrm{c}, \mathrm{k}}(\mathrm{n}=466)$

Daily
Weekly
Monthly
I do not play

39 (8.4)

57 (12.2)

97 (20.8)

257 (55.2)

$16(3.4)$

$343(73.3)$

125 (26.7)

70 (55.6)

56 (44.4)

Ways of nutritional education by digital games ${ }^{\mathrm{a}, \mathrm{m}}(\mathrm{n}=463)$

$\begin{array}{ll}\text { Yes } & 343(73.3) \\ \text { No } & 125(26.7) \\ \text { ays of nutritional education by digital games } & \\ \text { Quiz } & \\ \text { Tasks } & \\ \text { Movies } & 323(69.8) \\ \text { Mates } & 333(71.9) \\ \text { Other } & 150(32.4) \\ \text { No learning } & 98(21.2) \\ \end{array}$

$273(79.8)$

$69(20.2)$

$72(21.6)$
$47(14.1)$
$47(14.1)$
$163(48.9)$
$4(1.2)$

$17(5.0)$

$25(7.3)$

64 (18.7)

225 (65.8)

$11(3.2)$

$$
\begin{aligned}
& 253(74.9) \\
& 257(76.0) \\
& 114(33.7) \\
& 71(21.0) \\
& 38(11.2) \\
& 12(3.6)
\end{aligned}
$$

$22(17.7)$

32 (25.8)

33 (26.6)

$32(25.8)$

$5(4.0)$

Nutritional education by digital games ${ }^{c, l}(n=468)$

$\begin{array}{ll}25(20.3) & .76 \\ 19(15.4) & .72 \\ 18(14.6) & .89 \\ 57(46.3) & .62 \\ 4(3.3) & .14\end{array}$

$<.001$

$<.001$ .06

$<.001$

.67 


\begin{tabular}{|c|c|c|c|c|}
\hline Digital gameplay and characteristics & All, n (\%) & Female, n (\%) & Male, n (\%) & $P$ value \\
\hline No answer applies & $15(3.2)$ & $12(3.6)$ & $3(2.4)$ & .54 \\
\hline
\end{tabular}

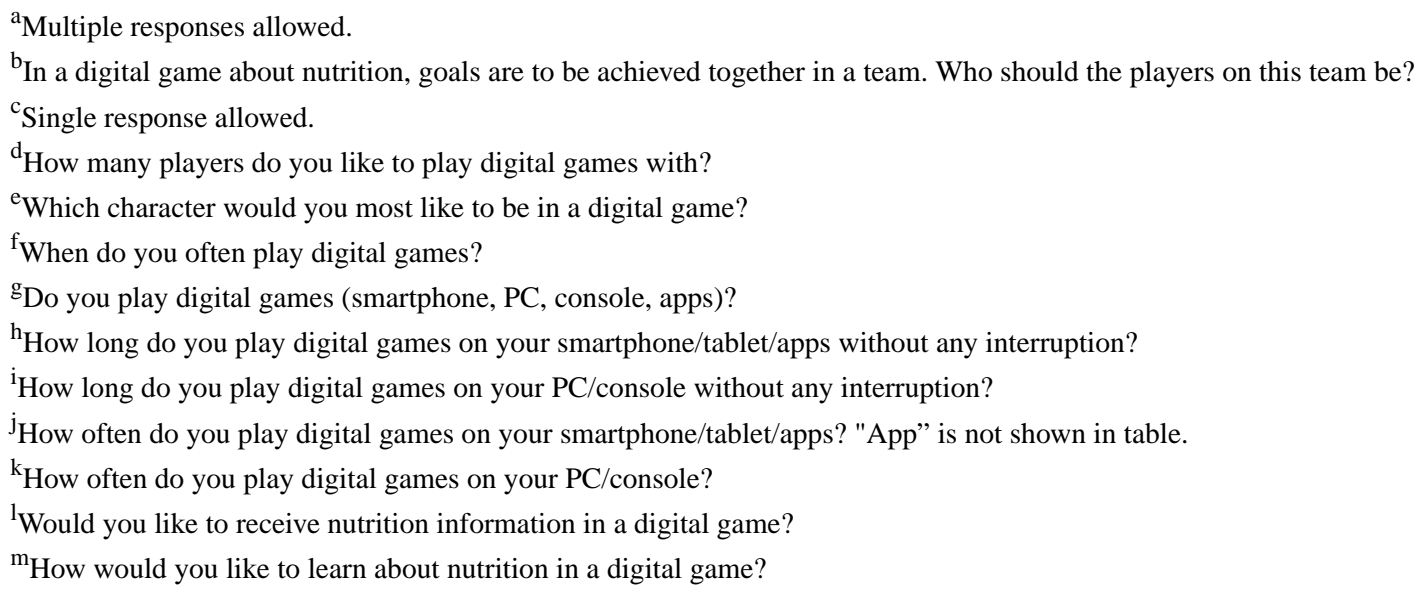

\section{Discussion}

\section{Principal Findings}

This survey reports findings on nutritional information strategies and motives, preferences, and behaviors for digital gameplay among more than 450 young adults, mainly university students. In total, 62.6\% (293/468) of the participants reported playing digital games. Our findings are in line with data from the United States. According to data from the Pew Research Center, $60 \%$ of young American adults aged between 18 and 29 years play video games often or sometimes (computer, television, game console, portable device), with young men more likely to play video games than young women [20,21]. In contrast, data from an online survey among 900 Finish and Belgian university students and employees (mean age 26.8 years) showed that only one-third of participants play mobile games [22].

Regarding device preferences, more participants reported using smartphones or tablets than PCs or consoles on a daily and weekly basis. These findings are different than results from a survey among 292 participants at a US gaming convention (68.6\% male; mean age 34.2 [SD 10.6] years) showing that the computer was the preferred platform for gameplay [23]. According to the literature, smartphones, PCs, and consoles are the most preferred gaming platforms in Germany [24].

Most of the survey sample who play digital games reported doing so for more than one hour continuously on PCs or consoles. These findings are similar to data from Arnaez et al [23] demonstrating that American adults spent on average at least 2 hours per day on computers or consoles for gameplay. Lopez-Fernandez et al [22] revealed that the average time of smartphone gameplay was almost 2 hours per day, which is longer than our survey participants indicated.

\section{Nutritional Information: Interest and Acquisition}

This survey revealed that the most used nutritional information sources currently were internet $(79.7 \%)$ and books and newspapers $(63.8 \%)$, followed by partner and family $(46.7 \%)$, friends $(43.0 \%)$, university and workplace $(35.1 \%)$, and social networks $(34.4 \%)$. Findings are in line with results from a cross-sectional study about nutritional information sources among 192 Ghanaian young adults (51.0\% women; 66\% students) aged between 18 and 25 years [25]. The study showed that the most consistently used nutritional sources were online resources $(92.7 \%)$, followed by traditional media $(58.3 \%)$, peers and friends $(29.7 \%)$, family members $(29.7 \%)$, and health care professionals (4.7\%) [25]. According to a survey by Percheski and Hargittai [26], social networks (89.5\%) were the most used source of health information among 1060 US university students, followed by online $(78.4 \%)$, medical professionals $(75.5 \%)$, and traditional media (74.6\%). With respect to the interpretation and comparison of our survey with other data, it must be acknowledged that the classification of nutritional information sources into digital and nondigital varies between studies. In addition, there might be some overlaps regarding the single items - for instance, the social networks resource might include digital resources (eg, internet, apps) or nondigital ones (eg, partner and family, friends). Furthermore, the subanalysis showed that there are gender-specific differences in the acquisition of nutritional information among our survey population. The literature on health information-seeking behaviors among university students in the United States indicates that women are more likely than men to use online resources or seek health information in general [26-28], which also applies to our survey results. In general, this survey as well as the literature indicate that both digital and nondigital tools and settings are used and desired for nutrition information. Considering this aspect, digital and nondigital nutrition information sources complement one another and should be offered in parallel.

It was shown that nearly three-quarters $(73.3 \%)$ of participants indicated they were interested in receiving nutritional information through digital games (Table 3). This is in line with a focus group study showing that young adults (mean age 23.1 [SD 2.7] years) perceive mobile games as a reasonable nutritional education approach [6]. According to a previous survey, this interest is lower in children and adolescents [19]. In total, $0.4 \%$ of participants reported currently using digital games for obtaining nutritional information and $10.0 \%$ reported desiring them additionally. When asked whether they would like to receive nutritional information during digital gameplay, more than $70 \%$ of participants, especially women, responded 
yes. This question was asked at the beginning of the gameplay section, where we added a scenario to allow participants to better immerse themselves in the questions. However, the scenario might have biased participant response behavior. Finally, we assume the responses are not in contrast to each other.

Until now, data regarding the sources of nutritional information in Germany has been limited. According to a survey on German dietary and shopping behaviors conducted on behalf of the Federal Ministry of Food and Agriculture in 2017, 69\% of participants preferred receiving nutritional information personally at the point of sale, whereas $42 \%$ preferred an internet/online search [29]. Social media were used for information by $14 \%$ ( $31 \%$ aged from 18 to 29 years) of the survey population. [29]. These findings are in line with this survey revealing that digital nutritional information is collected primarily via the internet and social networks, while books and newspapers, partner and family, and friends were the most preferred nondigital sources.

The relevance of nondigital information channels was confirmed by the German federal report [29]. European data indicates a similar picture as friends and newspapers are the most frequently used nutritional information sources for adults [30]. Our findings are in line with data from Canada demonstrating that $94 \%$ of households count at least one person using the internet for health guidance [31]. According to a cross-sectional study with almost 200 young adults, online resources were the most popular nutritional information sources, while family members and friends/peers played a minor role [25]. Moreover, most participants indicated that the most reliable sources for nutritional information are health care professionals [25]. As the option nutritional expert was not provided within this survey, there are no comparable data available.

Most survey participants reported wanting digital nutritional information sources (television, internet, social networks, apps, and digital games) in addition to the sources currently used (Table 2). This finding might be of added value in terms of developing a digital nutritional game for adults, as online information resources are available and accessible for myriad demographics with a simple dissemination [25]. Therefore, it could be assumed that young adults may be a suitable target group for nutritional education through serious games.

Since consideration of the target groups' needs, interests, perspectives, and preferences is crucial for the development of effective health games [16,32], data about learning preferences were collected in this survey as well. The majority of participants stated wanting to learn about nutrition in a digital game by playing a quiz or by solving tasks, which is consistent with data among young adults [6] and the younger population [19].

Our data showed that adults mainly prefer a human being or fantasy character in digital games. The preference for fantasy contexts or fantasy characters in serious games has already been shown for children [13,19] and students [33]. Besides the motivational nature of fantasy [13], fantasy-related contents used in video games improved the transfer of nutritional knowledge in children significantly more than no fantasy contexts [34]. Presented preferences should be considered for the development and design of a game for young adults [35]. A review on the usability of health-related games indicated that one of the main limitations of games for health is their lack in customization [36].

\section{Strengths and Limitations}

This survey addresses a rather large sample of young adults, mainly university students, an underrepresented target group in gaming research and nutritional education interventions $[37,38]$. Our overall purpose was to assess young adult preferences, motives, and behaviors regarding a serious game for nutritional education. The questionnaire was developed by a multidisciplinary team of scientists to ensure that perspectives of relevant disciplines were considered. Since there was no validated questionnaire available for the purpose of our survey, we developed a questionnaire from scratch according to common recommendations. A previous version of the questionnaire was pretested internally by university students. However, there are some limitations that need to be mentioned. The questionnaire also covered technical game design aspects, and we refrained from presenting these data. Moreover, there might have been some overlaps regarding the response items within the questionnaire (eg, Table 2, questions 1 and 2), because participants might be not able to distinguish between, for instance, apps and digital games, since digital games can be apps and vice versa. This might be an explanation for the observation that only a few participants used $(0.4 \%)$ or wanted $(10.0 \%)$ a digital game for nutritional information, but almost three-quarters $(73.3 \%)$ wanted nutritional information during the gameplay of a serious nutritional game. Another explanation for this result might be that questions were asked in different contexts. Moreover, data regarding digital media consumption (frequency and duration) might be limited, since we did not discriminate between digital gameplay on weekdays and weekends. The online survey might be prone to selection bias, as participation is limited to those with internet access $[39,40]$. Furthermore, the survey invitation was mainly distributed via university-associated channels in the large city of Munich (Bavaria) resulting in more than $80 \%$ university students. Because the survey was not restricted to university students, nonstudents also participated. The majority of nonstudent participants indicated they were an academic (eg, graduates) or academic staff (eg, research assistants). Moreover, the sample size is mainly female, with more than $70 \%$ women. Therefore, presented data (eg, body weight, body mass index) are not representative for young adults or university students in Germany. All data were obtained by self-report.

\section{Implications for Research and Practice}

This survey revealed novel findings regarding digital gameplay in the context of nutritional education among a survey sample of more than 450 young adults, primarily female university students, in Germany. Since the game design process often lacks in the consideration of the target group's preferences, referring to this survey data might be useful for the design of a target group-specific game for young adults, especially females. Further aspects such as behavioral change techniques (eg, goal setting, self-monitoring) should be incorporated into the 
development of educational games. Moreover, previous studies have found young adults prefer simple and quick interfaces, gaming reward strategies, competitive incentives (eg, leader boards), and notifications [6].

As digital gameplay can be affected by high attrition rates, the implementation of different game elements (eg, simulation, adventure, and quizzes) should be considered. Compared with quizzes and adventures, simulations are perceived as more beneficial for educational purposes by students aged 18 to 33 years [41]. Finally, the target group's preferences need to be considered during all development and design stages of serious games [16].

Since the scientific evidence on the effects and effectiveness of serious games on nutritional outcomes (eg, knowledge, behavior) among young adults is limited, there is a need for addressing this topic within high-quality and long-term studies in the future $[12,18]$. Behavior changes are multifactorial processes. Therefore, it remains unclear whether an increase in nutritional knowledge can affect dietary behaviors at all. For instance, literature on students (mean age 21.8 [SD 1.9] years) showed that knowledge of healthy foods does not lead to the consumption of healthy snacks [42].

The design and development of serious games is a cost- and time-intensive process that requires the involvement of both experts and target groups $[43,44]$. Baranowski et al [43] reported that it takes three-and-a-half years to develop a health-related behavior change game. Serious games released by commercial vendors might be more attractive to players because of high-end graphical user interfaces, multiple levels, animation, and interactivity than their counterparts from research facilities. This may also have an impact on the adherence since fun affects the intrinsic motivation and intention to change behavior.

\section{Conclusions}

This survey showed that mainly male university students play digital games, but they are less willing to get nutritional education via serious games compared with female students. Nondigital tools and settings like books, newspapers, university, and workplace are used and desired for nutritional education by young adults. A digital game might have potential as a tool for nutritional information among both male and female young adults and university students, for instance, in the workplace and university environment. Further research among representative survey samples is warranted to draw final and generalizable conclusions regarding the demand and acceptability of serious games in the context of nutritional information. Finally, further research should address gender-specific differences in nutritional information acquisition and gameplay preferences, motives, and behaviors.

\section{Acknowledgments}

The authors acknowledge all survey participants and cooperation partners at the Technical University of Munich, with special thanks to Prof Jutta Roosen, Prof Susanne Ihsen, Felicitas Dischl, Lea Schneider, Bernhard Mohr, Katharina Scheibl, and Christoph Lingl. This work was supported by the enable Cluster, funded by the German Federal Ministry of Education and Research (grant: 01EA1409H; enable publication: 035).

\section{Conflicts of Interest}

None declared.

\section{References}

1. Blüher M. Obesity: global epidemiology and pathogenesis. Nat Rev Endocrinol 2019 May;15(5):288-298. [doi: 10.1038/s41574-019-0176-8] [Medline: 30814686]

2. European Union. 2016 Oct 20. European Health Interview Survey-Almost 1 adult in 6 in the EU is considered obese: Share of obesity increases with age and decreases with education level URL: https://ec.europa.eu/eurostat/documents/ 2995521/7700898/3-20102016-BP-EN.pdf/c26b037b-d5f3-4c05-89c1-00bf0b98d646 [accessed 2020-05-10]

3. Munt AE, Partridge SR, Allman-Farinelli M. The barriers and enablers of healthy eating among young adults: a missing piece of the obesity puzzle: A scoping review. Obes Rev 2017 Dec;18(1):1-17. [doi: 10.1111/obr.12472] [Medline: 27764897]

4. Ernst J, Arens-Azevêdo U, Bitzer B, Bosy-Westphal A, de Zwaan M, Egert S, Buyken AE for the German Obesity Society (DAG), German Diabetes Society (DDG), German Nutrition Society. Quantitative recommendation on sugar intake in Germany: short version of the consensus paper by the German Obesity Society (DAG), German Diabetes Society (DDG) and German Nutrition Society (DGE). Ernahrungs Umschau 2019;66(2):26-34. [doi: 10.1159/isbn.978-3-8055-9961-0]

5. Serdula MK, Gillespie C, Kettel-Khan L, Farris R, Seymour J, Denny C. Trends in fruit and vegetable consumption among adults in the United States: behavioral risk factor surveillance system, 1994-2000. Am J Public Health 2004 Jun;94(6):1014-1018. [Medline: 15249308]

6. Nour MM, Rouf AS, Allman-Farinelli M. Exploring young adult perspectives on the use of gamification and social media in a smartphone platform for improving vegetable intake. Appetite 2018 Jan 01;120:547-556. [doi: 10.1016/j.appet.2017.10.016] [Medline: 29032184]

7. Nationale Verzehrsstudie II. Ernährung 2008 Feb;2(2):77-81. [doi: 10.1007/s12082-008-0148-1]

8. Rose D, Heller MC, Roberto CA. Position of the Society for Nutrition Education and Behavior: The Importance of Including Environmental Sustainability in Dietary Guidance. J Nutr Educ Behav 2019 Jan;51(1):3-15 [FREE Full text] [doi: 10.1016/j.jneb.2018.07.006] [Medline: 30635107] 
9. Contento I. Review of nutrition education research in the Journal of Nutrition Education and Behavior, 1998 To 2007. J Nutr Educ Behav 2008;40(6):331-340. [doi: 10.1016/j.jneb.2008.06.001] [Medline: 18984488]

10. Contento I, Balch GI, Bronner YL, Lytle LA, Maloney SK, Olson CM, et al. The effectiveness of nutrition education and implications for nutrition education policy, programs, and research: a review of research. J Nutr Educ 1995;26(6):277-418 [FREE Full text]

11. Brace AM, De Andrade FC, Finkelstein B. Assessing the effectiveness of nutrition interventions implemented among US college students to promote healthy behaviors: A systematic review. Nutr Health 2018 Sep;24(3):171-181. [doi: $\underline{10.1177 / 0260106018785528]}$ [Medline: $\underline{\text { 30014743] }}$

12. Nour M, Yeung SH, Partridge S, Allman-Farinelli M. A narrative review of social media and game-based nutrition interventions targeted at young adults. J Acad Nutr Diet 2017 May;117(5):735-752. [doi: 10.1016/j.jand.2016.12.014] [Medline: 28238894]

13. Baranowski T, Buday R, Thompson DI, Baranowski J. Playing for real: video games and stories for health-related behavior change. Am J Prev Med 2008 Jan;34(1):74-82 [FREE Full text] [doi: 10.1016/j.amepre.2007.09.027] [Medline: 18083454]

14. Baranowski T, Ryan C, Hoyos-Cespedes A, Lu AS. Nutrition education and dietary behavior change games: a scoping review. Games Health J 2019 Jun;8(3):153-176. [doi: 10.1089/g4h.2018.0070] [Medline: 30339086]

15. Jahresreport der Computer- und Videospielbranche in Deutschland 2017 (Annual Report of the Computer and Video Games Industry in Germany 2017). Berlin: Bundesverband Interaktive Unterhaltungssoftware; 2017. URL: https://www.game.de/ wp-content/uploads/2017/09/game Jahresreport 2017 interaktiv.pdf [accessed 2020-05-10]

16. DeSmet A, Thompson D, Baranowski T, Palmeira A, Verloigne M. Is participatory design associated with the effectiveness of serious digital games for healthy lifestyle promotion? a meta-analysis. J Med Internet Res 2016 Apr 29;18(4):e94 [FREE Full text] [doi: 10.2196/jmir.4444] [Medline: 27129447]

17. Peng W. Design and evaluation of a computer game to promote a healthy diet for young adults. Health Commun 2009 Mar;24(2):115-127. [doi: 10.1080/10410230802676490] [Medline: 19280455]

18. Shiyko M, Hallinan S, Seif EM, Subramanian S, Castaneda-Sceppa C. Effects of playing a serious computer game on body mass index and nutrition knowledge in women. JMIR Serious Games 2016 Jun 02;4(1):e8 [FREE Full text] [doi: 10.2196/games.4977] [Medline: 27255497]

19. Holzmann S, Dischl F, Schäfer H, Groh G, Hauner H, Holzapfel C. Digital gaming for nutritional education: a survey on preferences, motives, and needs of children and adolescents. JMIR Form Res 2019;3(1):A. [Medline: 30758290]

20. Brown A. Who plays video games? Younger men, but many others too. Washington: Pew Internet and American Life Project; 2017 Sep 11. URL: https://www.pewresearch.org/fact-tank/2017/09/11/ younger-men-play-video-games-but-so-do-a-diverse-group-of-other-americans/ [accessed 2020-05-10]

21. Duggan M. Gaming and gamers. Washington: Pew Internet and American Life Project; 2015 Dec 15. URL: https://www. pewresearch.org/internet/wp-content/uploads/sites/9/2015/12/PI 2015-12-15 gaming-and-gamers FINAL.pdf [accessed 2020-05-10]

22. Lopez-Fernandez O, Männikkö N, Kääriäinen M, Griffiths MD, Kuss DJ. Mobile gaming and problematic smartphone use: a comparative study between Belgium and Finland. J Behav Addict 2018 Mar 01;7(1):88-99 [FREE Full text] [doi: 10.1556/2006.6.2017.080] [Medline: 29313732]

23. Arnaez J, Frey G, Cothran D, Lion M, Chomistek A. Physical wellness among gaming adults: cross-sectional study. JMIR Serious Games 2018 Jun 12;6(2):e12 [FREE Full text] [doi: 10.2196/games.9571] [Medline: 29895516]

24. Jahresreport der deutschen Games-Branche 2018 (Annual Report of the German Games Industry 2018). Berlin: Verband der deutschen Games-Branche; 2018. URL: https://www.game.de/wp-content/uploads/2018/08/ Jahresreport-der-deutschen-Games-Branche-2018.pdf [accessed 2020-05-10]

25. Quaidoo EY, Ohemeng A, Amankwah-Poku M. Sources of nutrition information and level of nutrition knowledge among young adults in the Accra metropolis. BMC Public Health 2018 Nov 29;18(1):1323 [FREE Full text] [doi: 10.1186/s12889-018-6159-1] [Medline: 30497442]

26. Percheski C, Hargittai E. Health information-seeking in the digital age. J Am Coll Health 2011;59(5):379-386. [doi: 10.1080/07448481.2010.513406] [Medline: 21500056]

27. Escoffery C, Miner KR, Adame DD, Butler S, McCormick L, Mendell E. Internet use for health information among college students. J Am Coll Health 2005;53(4):183-188. [doi: 10.3200/JACH.53.4.183-188] [Medline: 15663067]

28. Ogan CL, Ozakca M, Groshek J. Embedding the internet in the lives of college students: online and offline behavior. Soc Sci Comp Rev 2008;26(2):170-177. [doi: 10.1177/0894439307306129]

29. Deutschland, wie es isst (Germany as it eats): Der BMEL-Ernährungsreport 2018. Berlin: Bundesministerium für Ernährung und Landwirtschaft; 2017 Dec. URL: https://www.nqz.de/fileadmin/nqz/publikationsdateien/Ernaehrungsreport2018.pdf [accessed 2020-05-10]

30. Lappalainen R, Kearney J, Gibney M. A pan EU survey of consumer attitudes to food, nutrition and health: an overview. Food Qual Pref 1998 Nov;9(6):467-478. [doi: 10.1016/s0950-3293(98)00018-4]

31. Statistics Canada. Canadian Internet Use Survey 2018 URL: https://www150.statcan.gc.ca/n1/daily-quotidien/191029/ dq191029a-eng.htm [accessed 2020-05-18] 
32. Thompson D. Talk to me, please! The importance of qualitative research to games for health. Games Health J 2014 Jun;3(3):117-118. [doi: 10.1089/g4h.2014.0023] [Medline: 26196170]

33. Chang HY, Wong LL, Yap KZ, Yap KY. Gaming preferences, motivations, and experiences of pharmacy students in Asia. Games Health J 2016 Feb;5(1):40-49. [doi: 10.1089/g4h.2015.0028] [Medline: 26795233]

34. Parker LE, Lepper MR. Effects of fantasy contexts on children's learning and motivation: making learning more fun. J Pers Soc Psychol 1992 Apr;62(4):625-633. [doi: 10.1037//0022-3514.62.4.625] [Medline: 1583588]

35. Schäfer H, Plecher D, Holzmann S, Groh G, Klinker G, Holzapfel C, et al. NUDGE: nutritional digital games in Enable. 2017 Presented at: Positive Gaming: Workshop on Gamification and Games for Wellbeing; 2017; Amsterdam.

36. Lu AS, Kharrazi H. A state-of-the-art systematic content analysis of games for health. Games Health J 2018 Feb;7(1):1-15. [doi: 10.1089/g4h.2017.0095] [Medline: 29293368]

37. Miskovsky MJ. Lessons Learned When Evaluating Web-based Nutrition Education in College Freshmen. J Nurse Pract 2012 Feb;8(2):123-128. [doi: 10.1016/j.nurpra.2011.09.019]

38. DeSmet A, Van Ryckeghem D, Compernolle S, Baranowski T, Thompson D, Crombez G, et al. A meta-analysis of serious digital games for healthy lifestyle promotion. Prev Med 2014 Dec;69:95-107. [doi: 10.1016/j.ypmed.2014.08.026] [Medline: 25172024]

39. Whitaker C, Stevelink S, Fear N. The use of facebook in recruiting participants for health research purposes: a systematic review. J Med Internet Res 2017 Aug 28;19(8):e290 [FREE Full text] [doi: 10.2196/jmir.7071] [Medline: 28851679]

40. Tai X, Smith AM, McGeer AJ, Dubé E, Holness DL, Katz K, et al. Comparison of response rates on invitation mode of a web-based survey on influenza vaccine adverse events among healthcare workers: a pilot study. BMC Med Res Methodol 2018 Jun 20;18(1):59 [FREE Full text] [doi: 10.1186/s12874-018-0524-8] [Medline: 29925324]

41. Riemer V, Schrader C. Learning with quizzes, simulations, and adventures: students' attitudes, perceptions and intentions to learn with different types of serious games. Comp Educ 2015 Oct;88:160-168. [doi: 10.1016/j.compedu.2015.05.003]

42. McArthur LH, Valentino A, Holbert D. Knowledge of healthy foods does not translate to healthy snack consumption among exercise science undergraduates. Nutr Health 2017 Jun;23(2):103-110. [doi: 10.1177/0260106017704796] [Medline: 28413923]

43. Baranowski T, Ryan C, Hoyos-Cespedes A, Lu AS. Nutrition education and dietary behavior change games: a scoping review. Games Health J 2019 Jun;8(3):153-176. [doi: 10.1089/g4h.2018.0070] [Medline: $\underline{30339086]}$

44. Baranowski T, Buday R, Thompson DI, Baranowski J. Playing for real: video games and stories for health-related behavior change. Am J Prev Med 2008 Jan;34(1):74-82 [FREE Full text] [doi: 10.1016/j.amepre.2007.09.027] [Medline: 18083454]

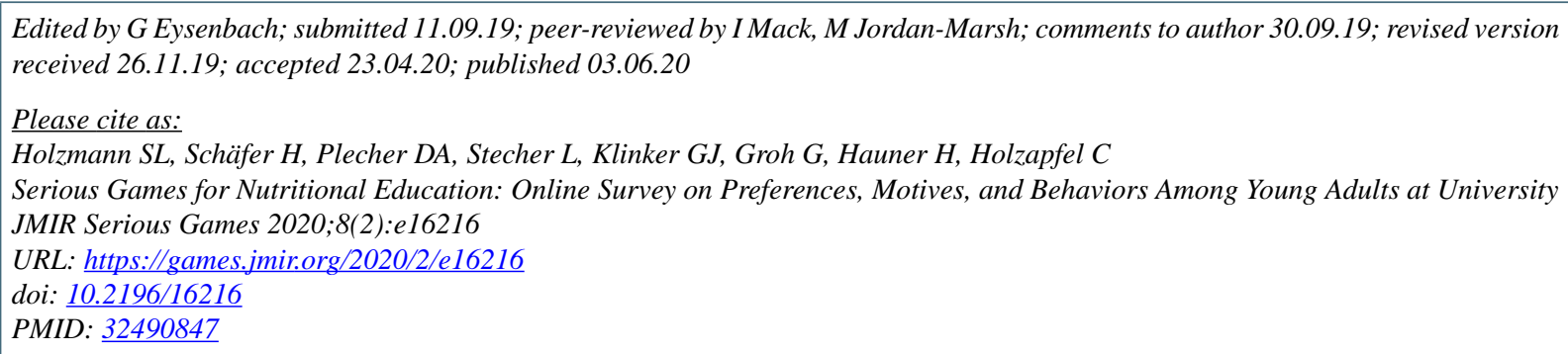

(CSophie Laura Holzmann, Hanna Schäfer, David Alexander Plecher, Lynne Stecher, Gudrun Johanna Klinker, Georg Groh, Hans Hauner, Christina Holzapfel. Originally published in JMIR Serious Games (http://games.jmir.org), 03.06.2020. This is an open-access article distributed under the terms of the Creative Commons Attribution License (https://creativecommons.org/licenses/by/4.0/), which permits unrestricted use, distribution, and reproduction in any medium, provided the original work, first published in JMIR Serious Games, is properly cited. The complete bibliographic information, a link to the original publication on http://games.jmir.org, as well as this copyright and license information must be included. 